\title{
Cervical Pregnancy in a Primigravida Patient without Risk Factors: A Case Report
}

\author{
Dieudonné Sengeyi Mushengezi Amani ${ }^{1 *}$, Eloge Ilunga-Mbaya ${ }^{2}$, Francis Ebola Iyawa ${ }^{1}$, \\ Berry Kinkenda Nsiangangu ${ }^{1}$
}

${ }^{1}$ Obstetrics Service, Department of Gynecology and Obstetrics, University Clinics of Kinshasa, Lemba/Kinshasa XI/DRC, Unikin, Congo

${ }^{2}$ Gynecology Service, Department of Gynecology and Obstetrics, University Clinics of Kinshasa, Kinshasa XI, Unikin, Congo

Email: ^dsengeyi@gmail.com, elogeilungambaya@yahoo.fr

How to cite this paper: Amani, D.S.M. Ilunga-Mbaya, E., Iyawa, F.E. and Nsiangangu, B.K. (2020) Cervical Pregnancy in a Primigravida Patient without Risk Factors: A Case Report. Open Journal of Obstetrics and Gynecology, 10, 770-777.

https://doi.org/10.4236/ojog.2020.1060071

Received: April 29, 2020

Accepted: June 8, 2020

Published: June 11, 2020

Copyright $\odot 2020$ by author(s) and Scientific Research Publishing Inc. This work is licensed under the Creative Commons Attribution International License (CC BY 4.0).

http://creativecommons.org/licenses/by/4.0/

\begin{abstract}
Cervical pregnancy is defined as the implantation of the egg below of the internal cervical orifice, and remains a rare clinical entity which affects on average 1 out of 20,000 pregnancies worldwide. Its hemorrhagic complications are life-threatening in case of late diagnosis. It occurs mainly on a history of curettage or caesarian which are the most recognized risk factors. The objective pursued here is to discuss the possibility of the occurrence of this rare clinical entity in a primigravida without risk factors and the different therapeutic possibilities according to the technical platforms. Authors report a case of cervical pregnancy at 6 weeks' gestation occurring in a primigravida without risk factors who consulted at University clinics of Kinshasa (UCK) for a genital hemorrhage chart. The diagnosis was made using ultrasound and treatment provided by curettage followed by the placement of an intra-cervical foley tube for hemostatic purposes. Given its high mortality, the diagnosis must be early even in pregnant women without obvious risk factors. The diversity of therapeutic means gives practitioners a choice depending on the technical platform.
\end{abstract}

\section{Keywords}

Cervical Pregnancy, Risk Factors, Hemorrhage, Methotrexate

\section{Introduction}

Cervical pregnancy, is a rare form of ectopic pregnancy, and is defined as the implantation of the egg below the internal orifice of the cervix [1]. It remains a rare clinical entity which affects $0.2 \%$ of ectopic pregnancies [2]. 
Described for the first time in 1817, the hemorrhagic complications inherent in this ectopic implantation can be life-threatening [1] [3]. Because of its rarity, therapeutic attitudes remain greatly varied in the literature.

We report a case of cervical pregnancy at 6 weeks' gestation in a primigravida patient without risk factors, diagnosed by ultrasound and managed by curettage and intra cervical bloating using the Foley catheter. The aim is to discuss the possibility of occurrence in primigravidae without risk factors and present the different therapeutic possibilities available in our environments.

\section{Case Report Narrative}

Mrs F, a 27 years-old primigavida, had consulted at the UCK for vaginal bleeding in the context of an 8 weeks of delay in her menstruation, she also reported nausea, hypogastralgia and physical asthenia. Her history was mainly marked by an ovarian cystectomy and appendectomy in 2009.

Her story started 4 days before the examination with repeated vaginal bleeding for which she decided to consult at the UCK.

On her entry, the blood pressure was at $100 / 60 \mathrm{mmHg}$, pulse at 94 per minute, respiratory rate at 18 cycles per minute, temperature at $36.6^{\circ} \mathrm{C}$. She was moderately colored. At the abdominal examination inspection, there was a mid-umbilical scar and the abdomen was not bloated and flexible. Vulva inspection showed traces of old blood.

Speculum examination noted traces of blood covering the cervical orifice and, after cleaning, a nulliparous cervix was objectified without any changes due to trauma. At the vaginal examination we palpated a short and soft cervix, admitting the digital pulp at the external orifice, and a 6 weeks' pregnancy like enlarged uterus with tender lower ureteral points.

The diagnosis of a threatened abortion probably due to urinary tract infection was made. However, the Ultrasound performed noted an intra-cervical gestational sac containing an embryo of $5 \mathrm{~mm}$ of CRL with cardiac activity (Figure 1 and Figure 2).

As well as an empty uterine cavity (Figure 3 ).

The beta HCG level was $1513 \mathrm{IU} / \mathrm{ml}$. The blood count performed came back as follows: a hemoglobin at $11.8 \mathrm{mg} / \mathrm{dl}$, white blood cells (WBC) at 8300 elements $/ \mathrm{mm}^{3}$ with neutrophils predominance at 54.9 , platelets at 254.000 elements $/ \mathrm{mm}^{3}$, the blood group O Rhesus positive.

Urine analysis showed numerous leukocytes per field and several bacteria. According to the above-mentioned elements and giving the hemorrhagic risk linked to curettage or aspiration, we decided to proceed with medical treatment by methotrexate, in order to annihilate the trophoblastic activity and finally perform a safely intrauterine aspiration.

However, the evolution was marked by more frequent and abundant hemorrhagic episodes, which led to the indication of curettage followed by the placement of an intra-cervical Foley catheter bloated with at $30 \mathrm{ml}$ for tamponade. 


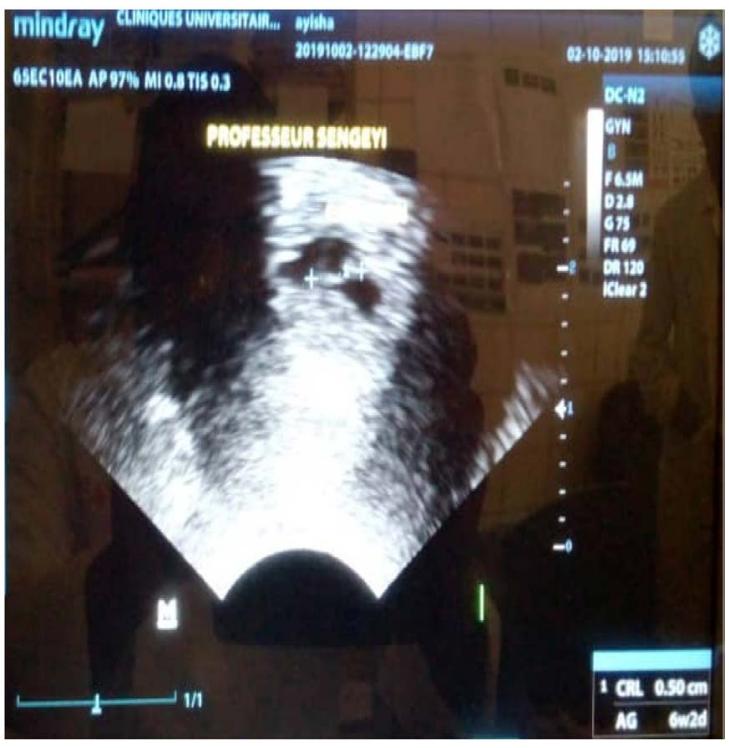

Figure 1. Intracervical pulsatile embryo.

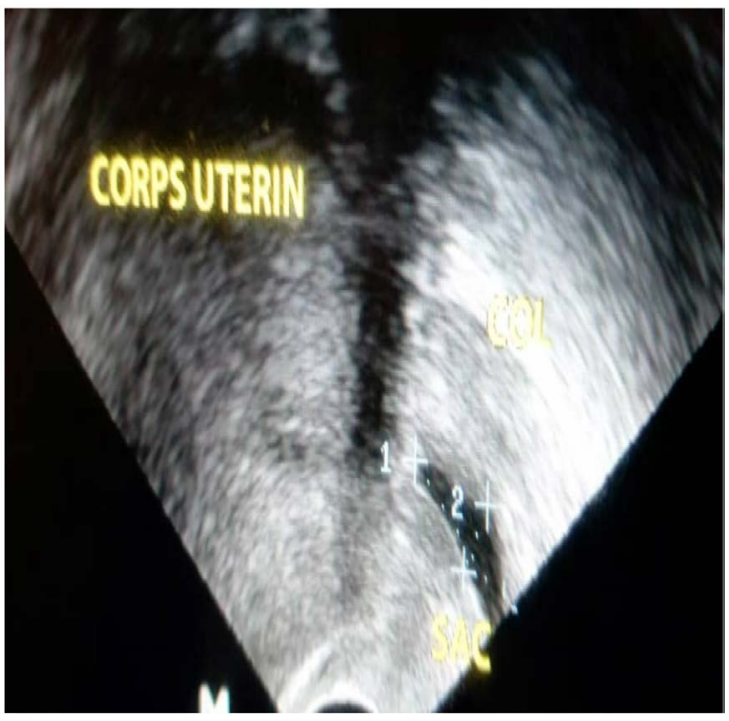

Figure 2. Intracervical gestational sac.

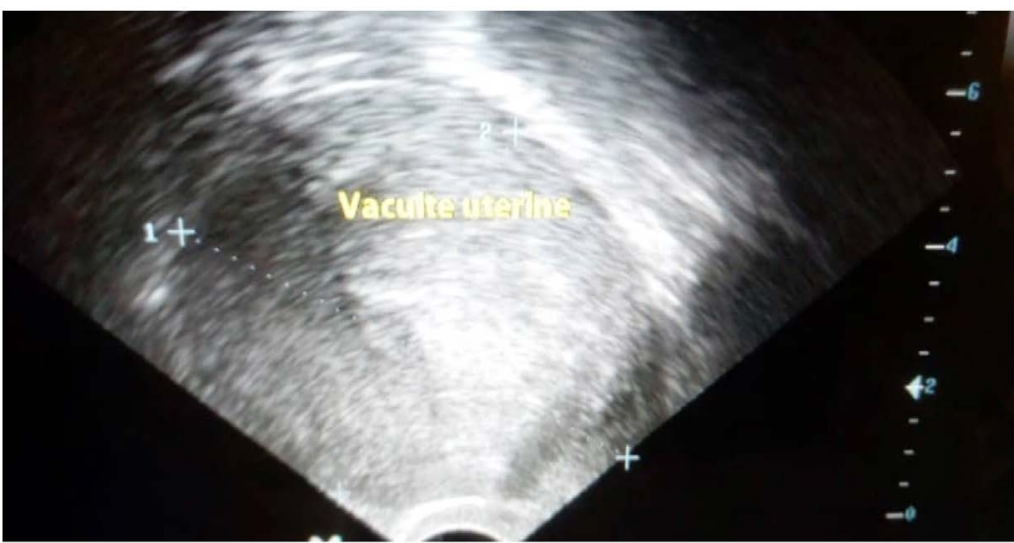

Figure 3. Uterine emptiness. 
When the speculum was placed during the curettage performed under general anesthesia, it was possible to objectify, after eversion of the cervix, cervical erosion (Figure 4) likely site of cervical implantation. Hemostasis was obtained after bloating of the number 18 probe intra-cervically (Figure 5) without selective arterial ligation.

Histopathologic examination revealed vestiges of primary placental chorionic villi with development of ecstatic nourishing vessels. Lack of decidualization of the cytogenic chorion.

The intra-cervical catheter was removed after 48 hours; the patient did not receive a transfusion.

The post-operative follow-up was simple and the patient was discharged from the hospital with a follow-up appointment scheduled in 48 hours.

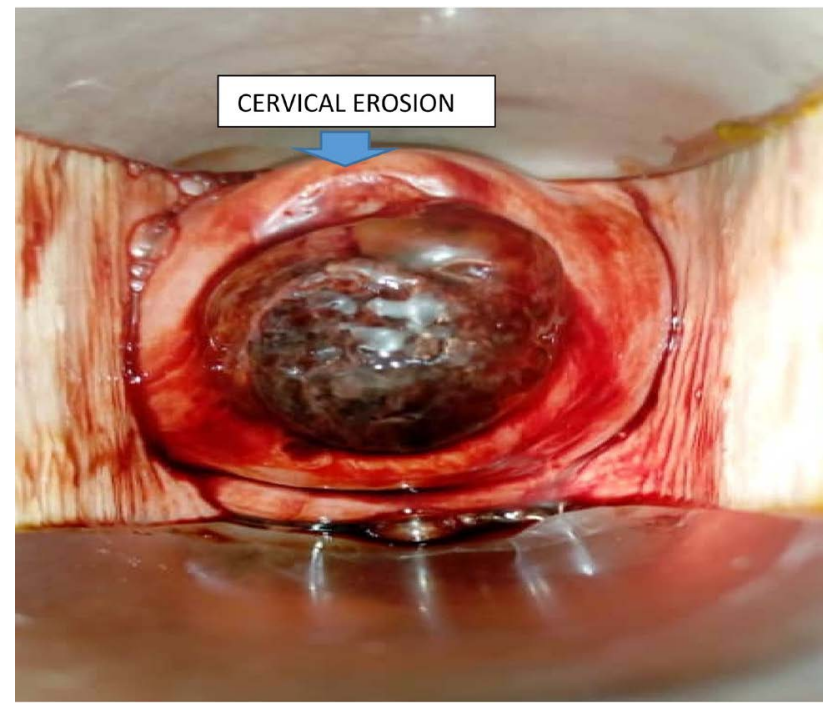

Figure 4. Externalized design product + cervical erosion.

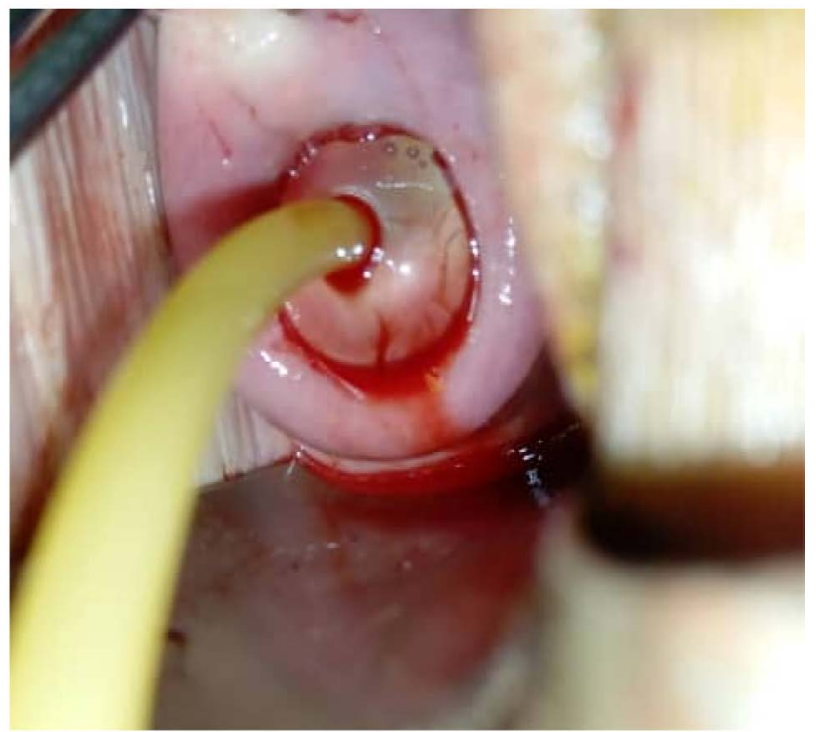

Figure 5. Intra-cervical ballooned Foley catheter. 


\section{Discussion}

Cervical and abdominal ectopic pregnancies are the rarest of the ectopic localizations. This term was only used in 1860 by ROTAKITANSKI [2].

Its diagnostic criteria were described by RUBIN in 1911 and are [1] [3]:

- presence of the endocervical glands next to the placental insertion,

- endocervical penetration of the chorionic villi,

- all or part of the placenta located below the level of penetration of the uterine vessels or below the level of reflection of the peritoneum on the anterior and posterior surfaces of the uterus,

- absence of the fetal parts inside the corporeal cavity.

Due to its rarity, its real incidence has never been determined, but it varies according to the series presented around 1 case/20,000 pregnancies [1] [4].

Several risk factors are attributed to it, however, the history of curettage is found in $50 \%$ to $90 \%$ of cases, according to data in the literature [1] [5] [6]. Other risk factors include: history of cesarean section, endometritis, intrauterine devices (IUDs), structural abnormalities of the uterine body, fibroids, synechiae, assisted reproductive technologies (ART) [5]. But for the present case the patient had none of these listed risk factors. However, KAMWENDO and al. [6] described a reduction in ectopic pregnancies that accompanied the reduction in the frequency of pelvic inflammatory disease (PID). We believe that given the young age of the patient and genital activity, very frequent PID in this age group could explain this occurrence.

The symptoms look like a threatened abortion or an inevitable abortion with painless metrorrhagia. However, the clinical diagnosis remains imprecise, hence the need for an Ultrasound or MRI [7].

The supra pubic route with a full bladder will allow better localization, but the vaginal route will reveal early ectopic gestational sac (GS). Nevertheless an intrauterine pregnancy in the process of expulsion can be confusing [4], but in the latter the uterus is enlarged and is the site of a hyperechoic mass corresponding to the pregnancy and the blood clot which is not the case in the present case.

The gravity of this pathology lies in its hemorrhagic complications (50\% mortality) due to the hypervascularisation of the cervix during pregnancy, its low content (only 20\%) in smooth muscle hence a low sensitivity of the fibrous tissue to mechanical and uterotonic stimulation [8].

Because of these complications which impede the vital prognosis, monitoring and treatment remain delicate. In the literature, therapeutic attitudes are not standardized. Because of its rarity, the literature is mainly made of clinical cases. Also the levels of evidence reached by the references used do not allow to be affirmative on any other attitude.

Hysterectomy is indicated today only in very hemorrhagic forms and on case of late diagnosis [2]. Faced with this growing concern for preserving fertility, several conservative therapies have been described over the past decade.

ILOKI and al. [3] described curettage accompanied by a compression method 
such as cerclage of the cervix or intra-cervical bloating by the Foley catheter which was used here. Until recently, ZAMBRANO and al. described a method of cervical tamponade using a double intra and exo cervical balloon successfully [9].

Some teams have described curettage preceded by preventive hypo gastric ligation or by vaginal ligation of the cervico-vaginal arteries for others [2]. Interventional radiology may, however, replace surgical ligatures by more or less selective embolization of the uterine arteries in the environment where this technique is available [5].

If the diagnosis is early at less than 6 weeks, hysteroscopic resection has also been perfomed by other teams [10]. Especially in heterotopic pregnancies (cervical and intrauterine) obtained through ART, it will allow on early forms where the trophoblastic is minimally invasive, to preserve the intrauterine pregnancy.

Methotrexate by general route and/or in situ is also most often used. But because of its high failure rate, some authors have established prognosis criteria for poor response including a beta HCG level greater than 10,000 MIU/ml, cardiac activity present, crown-rump length (CRL) greater than $10 \mathrm{~mm}$. It is often associated with Mifepristone [11] [12].

Potassium chloride (KCL), an equally effective foeticide, has been used in situ before or concurrently with methotrexate [12].

In the reported case, no risk factor was noted. PIZZOFERRATO [4] reports a possibility of cervical pregnancy reimplantation after the failure of a voluntary termination of drug pregnancy using Mifepristone. Indeed, the latter is known to inhibit the decidualization of the endometrium of the decidual capillaries. PID is also a risk factor for ectopic pregnancies in general [6]. We think that the young age of the patient puts her in the categories of most exposed to abortions and pelvic infections. Therapeutically, we first opted for a simple technique; rapid and minimally invasive especially because the pregnancy was very young.

\section{Conclusion}

Cervical pregnancy although rare is burdened with significant mortality because of its hemorrhagic complications. The diagnosis must be made early even in patients without obvious risk factors and this early diagnosis remains the key to therapeutic success. The diversity of the therapeutic means described gives the practitioner a choice depending on the technical background of the different environments.

\section{Acknowledgements}

We thank Professor Dr. Mutombo Baleka Alex, Chief of Gynecology service, University Clinics of Kinshasa for his review of the manuscript and English language editing.

\section{Formatting of Funding Sources}

This research did not receive any specific grant from funding agencies in the 
public, commercial, or not-for-profit sectors.

\section{Informed Consent}

The authors confirm that the patient has given her consent for this case report to be published.

\section{Conflicts of Interest}

The authors declare that they have no conflicts of interest in relation to this article.

\section{References}

[1] Khachani, I., Alami, M.H. and Bezad, R. (2017) Grossesse cervicale à 7 semaines d'aménorrhée: Défis de la prise en charge. The Pan African Medical Journal, 26, 1-5. https://doi.org/10.11604/pamj.2017.26.3.11055

[2] Prameela, R. and Dev, S. (2016) Cervical Ectopic Pregnancy: 10 Year Experience at Tertiary Care Hospital and Current Literature Review. International Journal of Reproduction, Contraception, Obstetrics and Gynecology, 5, 734-742. https://doi.org/10.18203/2320-1770.ijrcog20160575

[3] Iloki, L., Ibara, J., Koubaka, R. and Itoua, C. (2000) La grossesse cervicale: Diagnostic échographique et prise en charge. À propos d'un cas. Med Afr Noire, 47, 172-174.

[4] Pizzoferrato, A.C., Legendre, G., Demaria, F. and Benifla, J.L. (2012) La réimplantation cervicale de la grossesse, une complication méconnue des interruptions volontaires de grossesse. À propos d'un cas. Journal of Gynecology Obstetrics and $\mathrm{Hu}$ man Reproduction, 41, 587-590. https://doi.org/10.1016/j.jgyn.2012.07.002

[5] Hu, J., Tao, X., Yin, L. and Shi, Y. (2016) Successful Conservative Treatment of Cervical Pregnancy with Uterine Artery Embolization Followed by Curettage: A Report of 19 Cases. BJOG: An International Journal of Obstetrics \& Gynaecology, 123, 97-102. https://doi.org/10.1111/1471-0528.14005

[6] Kamwendo, F., Forslin, L., Bodin, L. and Danielsson, D. (2000) Epidemiology of Ectopic Pregnancy during a 28 Year Period and the Role of Pelvic Inflammatory Disease. Sexually Transmitted Infections, 76, 28-32.

https://doi.org/10.1136/sti.76.1.28

[7] Mouhajer, M., Obed, S. and Okpala, A.M. (2017) Cervical Ectopic Pregnancy in Resource Deprived Areas: A Rare and Difficult Diagnosis. Ghana Medical Journal, 51, 94-97.

[8] Munoz, J.L., Kalan, A. and Singh, K. (2018) Second Trimester Cervical Ectopic Pregnancy and Hemorrhage: A Case Report and Review of the Literature. Case Reports in Obstetrics and Gynecology, 2018, 1-3. https://doi.org/10.1155/2018/3860274

[9] Zambrano, N., Reilly, J., Moretti, M. and Lakhi, N. (2017) Double Balloon Cervical Ripening Catheter for Control of Massive Hemorrhage in a Cervical Ectopic Pregnancy. Case Reports in Obstetrics and Gynecology, 2017, 1-4. https://doi.org/10.1155/2017/9396075

[10] Vitale, S.G., Rapisarda, A.M.C. and Laganà, A.S. (2018) Cervical Ectopic Pregnancy: The Role of Hysteroscopy. In: Tinelli, A., Alonso Pacheco, L. and Haimovich, S., Eds., Hysteroscopy, Springer International Publishing, Berlin, 171-179. https://doi.org/10.1007/978-3-319-57559-9 18 
[11] Yamaguchi, M., Honda, R., Erdenebaatar, C., Monsur, M., Honda, T., Sakaguchi, I., et al. (2017) Treatment of Cervical Pregnancy with Ultrasound-Guided Local Methotrexate Injection. Ultrasound in Obstetrics \& Gynecology, 50, 781-787. https://doi.org/10.1002/uog.17384

[12] Hung, T.H., Shau, W.Y., Hsieh, T.T., Hsu, J.J., Soong, Y.K. and Jeng, C.J. (1998) Prognostic Factors for an Unsatisfactory Primary Methotrexate Treatment of Cervical Pregnancy: A Quantitative Review. Human Reproduction, 13, 2636-2642. https://doi.org/10.1093/humrep/13.9.2636 